\title{
The zone of sympatry and hybridization of Mytilus edulis and M. galloprovincialis, as described by intron length polymorphism at locus mac-1
}

\author{
CLAIRE DAGUIN, FRANÇOIS BONHOMME \& PHILIPPE BORSA* \\ Laboratoire Génome Populations Interactions and IRD, UMR 5000 CNRS, Station Méditerranéenne de \\ I'Environnement Littoral, 1 Quai de la Daurade, 34200 Sète, France
}

\begin{abstract}
Intron-size variation at the actin gene locus mac- 1 was used to characterize mussel, Mytilus spp., populations in the $\sim 2000-\mathrm{km}$ wide zone of contact and hybridization ('hybrid zone') between M. edulis and M. galloprovincialis in western Europe. Twenty-five samples were collected in 1995-99 in locations within the hybrid zone and from reference populations of each species. We used correspondence analysis on the matrix of allelic frequencies to determine which alleles are characteristic of each species, and to characterize samples along the genetic gradient between M. edulis and M. galloprovincialis. In the hybrid zone, some samples exhibited mac- 1 allele frequencies that were typical of M. edulis; other samples were distributed along the M. edulis/M. galloprovincialis gradient and displayed variable levels of intergradation that were not correlated with geography. Some of the latter samples exhibited significant heterozygote deficiencies. The simple admixture hypothesis (Wahlund effect) could not be rejected for two-fifths of the samples. The hybrid zone thus appeared as a mosaic of populations which are either pure M. edulis, or hybrid between M. galloprovincialis and M. edulis, or a mixture of the foregoing with M. galloprovincialis individuals. These results were consistent with published allozyme data, suggesting that they can be extended to the entire nuclear genome. M. edulis mac- 1 alleles were present at moderate frequency in Atlantic $M$. galloprovincialis, and at significantly lower frequency in some Mediterranean samples. This pattern was homogeneous over a broad geographical range within each basin. It was not evident that introgression of $M$. edulis into M. galloprovincialis presently occurs south of the zone of contact. We propose that the distinctness of the Atlantic $M$. galloprovincialis population results from past introgression by $M$. edulis alleles.
\end{abstract}

Keywords: heterozygote deficiency, hybrid zone, introgression, intron length polymorphism, Mytilus edulis, Mytilus galloprovincialis.

\section{Introduction}

Hybrid zones offer opportunities to study the genetics of differentiation and speciation because they allow divergent genomes to meet and interact, informing us about the endogenous and exogenous factors that are involved in maintaining the genetic integrity of a species (Barton \& Hewitt, 1989; Harrison, 1993; Arnold, 1997). In marine organisms, these processes are conditioned by peculiar life history traits, such as huge fecundity and dispersing larval stage, which provide potential for high

*Correspondence. E-mail: borsa@univ-montp2.fr selective mortality, high parent-to-offspring distance, and extensive gene flow.

The best documented cases of hybridization in the marine environment are probably those among pairs of species within the Mytilus edulis species complex (M. galloprovincialis $\times$ M. edulis: Skibinski et al., 1983; Coustau et al., 1991; Gardner, 1994; M. galloprovincialis $\times$ M. trossulus: McDonald \& Koehn, 1988; Inoue et al., 1997; Rawson et al., 1999; M. edulis $\times$ M. trossulus: Väinölä \& Hvilsom, 1991; Comesaña et al., 1999). A number of allozyme surveys have been conducted on the zone of sympatry/hybridization (referred to as 'hybrid zone' throughout this article) between $M$. edulis and M. galloprovincialis, which extends from the coasts of 
Scotland to the Basque Country (Seed, 1992; Gardner, 1994). Abrupt changes in allelic frequencies at allozyme loci that distinguish M. edulis from M. galloprovincialis have been reported between adjacent localities, as for instance in south-west Britain (Skibinski \& Beardmore, 1979; Skibinski et al., 1983). These are thought to reflect geographical variation in the opportunities for interbreeding, enhanced by geographically variable levels of selection on recruits (Skibinski \& Beardmore, 1979; Skibinski et al., 1983; Gardner, 1994). The distribution of multiple-locus genotypes suggests widespread though incomplete and geographically inconsistent intergradation (Skibinski \& Beardmore, 1979). Similar observations have been reported for populations along the French Atlantic coast (Coustau et al., 1991; Comesaña \& Sanjuan, 1997), where samples within the hybrid zone displayed allelic frequencies at the two most discriminative loci (Est-D and $M p i$ ) that were intermediate between those of M. edulis and M. galloprovincialis reference populations, while other samples were genetically similar to M. edulis. At other loci $(\mathrm{Odh}, \mathrm{Gpi})$, certain alleles appeared in higher frequency in hybrid zone samples as compared to both reference populations. Allozyme data thus depict the European zone of sympatry of $M$. edulis with $M$. galloprovincialis as a geographical mosaic of populations where a site harbours either a pure population of either species, or a hybrid population, or any mixture of the foregoing. $M$. edulis tends to occupy more sheltered habitats than M. galloprovincialis (Skibinski et al., 1983).

Outside the hybrid zone, allelic frequencies at loci $A p$, $G p i$, and $O d h$ differ between NE Atlantic and Mediterranean Mytilus galloprovincialis (Coustau et al., 1991; Sanjuan et al., 1994; Quesada et al., 1995c). An abrupt genetic transition between NE Atlantic and Mediterranean $M$. galloprovincialis is evident at allozyme loci (Quesada et al., 1995c), and for mitochondrial DNAs (Quesada et al., 1995a; Sanjuan et al., 1996). This indicates that NE Atlantic and Mediterranean populations of $M$. galloprovincialis are geographically separated, and that the present hybridization with M. edulis exclusively concerns the NE Atlantic form of M. galloprovincialis.

Mitochondrial (mt) DNA surveys have shown the introgression of Mytilus edulis-like mtDNA into M. galloprovincialis in south-west Britain, south of the hybrid zone in the north-eastern Atlantic, and even in the Mediterranean (Hilbish et al., 2000; Edwards \& Skibinski, 1987; Quesada et al., 1995b, 1998; Rawson \& Hilbish, 1995, 1998). MtDNA typical of Mediterranean $M$. galloprovincialis was generally absent in Atlantic $M$. galloprovincialis, being detected in only a putative hybrid population in south-west Britain (Rawson \& Hilbish, 1998; Hilbish et al., 2000). Quesada et al. (1998) provided similar results: both phylogenetic trees of maternal and paternal mtDNA haplotypes showed two distinct clusters of haplotypes, one dominating Mediterranean $M$. galloprovincialis and occasionally being present in Atlantic M. galloprovincialis, and the other containing all haplotypes found exclusively in M. edulis, together with haplotypes found in both Atlantic and Mediterranean forms of $M$. galloprovincialis. This apparently fits the distinction between type $D$ and type $A$ haplotypes, respectively (Rawson \& Hilbish, 1995; Hilbish et al., 2000). That most Atlantic, and a proportion of Mediterranean, M. galloprovincialis carry haplotypes of the $A$ haplogroup suggests they have been introgressed by $M$. edulis-like mtDNAs. The $A$ haplotypes found in $M$. galloprovincialis being however, absent from $M$. edulis, which harbours distinct $A$ haplotypes (Rawson \& Hilbish, 1998), suggests that this introgression is ancient and since then no mtDNA gene flow has been occurring between the two species.

Nuclear DNA markers are now available to study the genetics of Mytilus populations (Côrte-Real et al., 1994; Inoue et al., 1995, 1997; Beynon \& Skibinski, 1996; Rawson et al., 1996; Ohresser et al., 1997; Heath \& Hilbish, 1998). Studies intending to compare nuclear DNA with allozyme variation in marine species are interesting because of useful inferences that may arise from contrasting patterns in geographical variation (Karl \& Avise, 1992 - but see Hare et al., 1996; Pogson et al., 1995; Lemaire et al., 2000). Introns in particular are highly polymorphic parts of the nuclear genome; these markers are generally presumed to be neutral since they are noncoding. Also, linkage disequilibrium effects are expected to be extremely weak in outbreeding species with very large population sizes such as marine mussels. In contrast, selection has been documented at some allozyme loci in Mytilus spp. populations (Mitton \& Koehn, 1973; Diehl \& Koehn, 1985; Koehn \& Hilbish, 1987) and in other bivalves (e.g. Koehn et al., 1988; Gaffney, 1994).

The first intron of the mac-1 actin gene (Ohresser et al., 1997) exhibits considerable variability in length with 23 alleles detected so far in European Mytilus edulis and M. galloprovincialis (Daguin \& Borsa, 1999, 2000). This marker allows the distinction between populations of the two species $M$. edulis and $M$. galloprovincialis (Daguin \& Borsa, 1999). mac-1 therefore appears to be as discriminating as the two allozyme loci (namely, Est-D and $M p i$ ) that best distinguish M. galloprovincialis from M. edulis (Coustau et al., 1991; McDonald et al., 1991). Moreover, mac-1 data confirmed that M. galloprovincialis populations on either side of the Alboran Sea are genetically distinct (Daguin \& Borsa, 1999). The level of variability at locus $m a c-1$ at once allows it to be useful for the study of genetic variation within each 
species, while being virtually diagnostic between species. The diagnostic allozyme and other nuclear-DNA loci used so far in Mytilus spp. surveys do not have this advantage.

The objective of the present study was to document the geographical and genetic structure of the European hybrid zone using presumably neutral, nuclearDNA markers. For this, we characterized at locus mac-1 mussel populations sampled along the European Atlantic coasts, and we compared their allelic frequencies to those of reference populations sampled outside the zone of sympatry, using correspondence analysis. The distribution of heterozygous individuals in samples whose allelic frequencies were intermediate between those of Mytilus edulis and Atlantic M. gallo- provincialis yielded information about the extent of hybridization vs. simple admixture. The allele frequency patterns outside the hybrid zone were compared to those expected under scenarios of present or ancient introgression of $M$. edulis into M. galloprovincialis.

\section{Materials and methods}

\section{Collection of samples}

Mytilus spp. samples were collected in 1995-99 in 25 sites along the European and Moroccan Atlantic shores and in the Mediterranean sea (Fig. 1; sample sizes in Table 1). Twelve of these samples were from localities

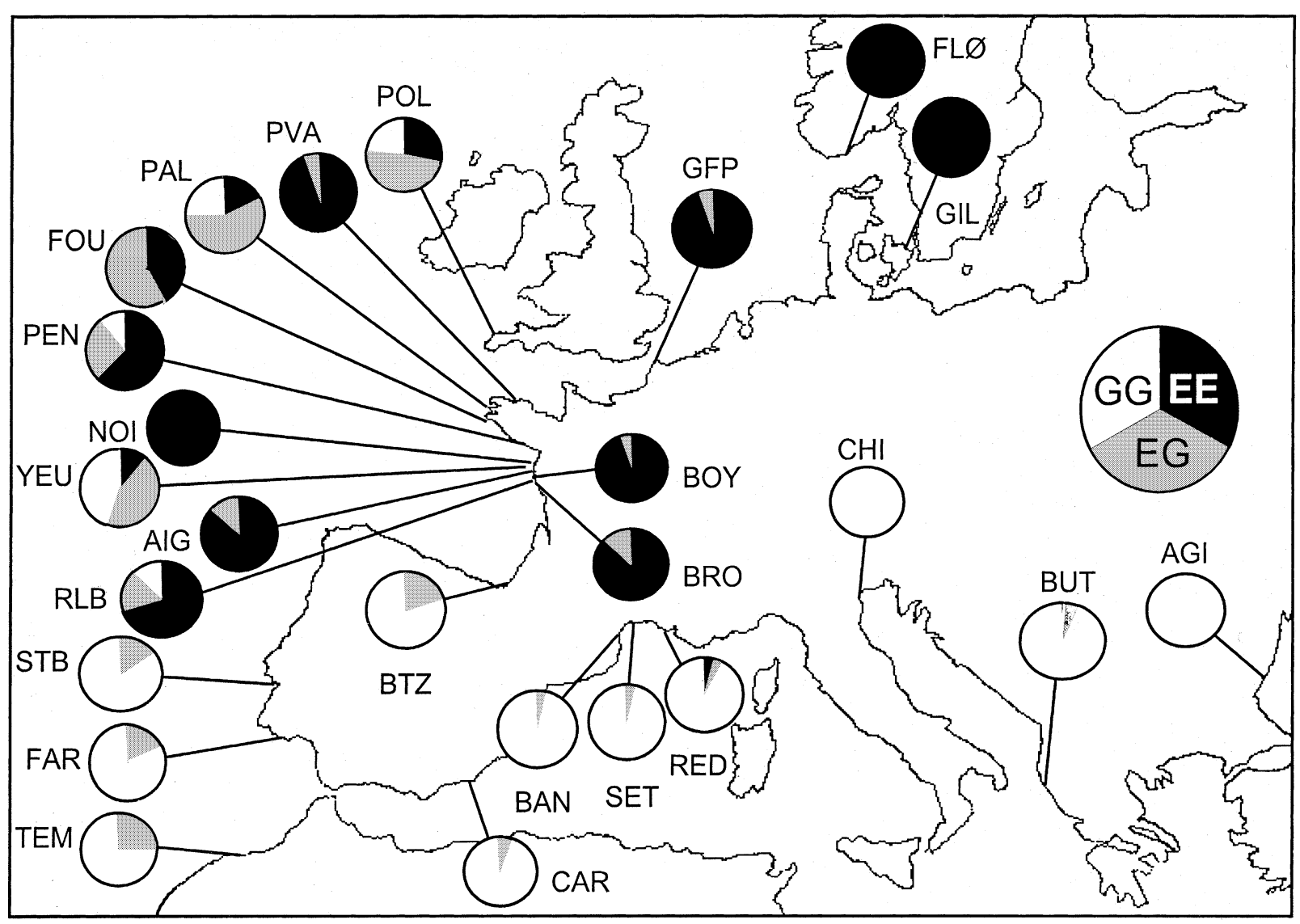

Fig. 1 Sampling localities for Mytilus spp. in the north-eastern Atlantic and the Mediterranean Sea. Genotypic composition of the samples after collapsing alleles characteristic of $M$. edulis and $M$. galloprovincialis (see text and Fig. 2) into classes $E$ and $G$, respectively, is also given. Allele $f 3$, which was private to sample AGI (Table 1) was included in $G$. FLØ: Flødevigen, Skagerrak, Norway; GIL: Gilleleje, Kattegat, Denmark; POL: Polzeath, Cornwall; GFP: Grand-Fort-Philippe, northern France; PVA: Pléneuf-Val-André, Brittany, France; PAL: La Palue, Brittany, France; FOU: La Forêt-Fouesnant, Brittany, France; PEN: Pénestin, Brittany, France; NOI: La Guérinière, Ile de Noirmoutier, Vendée, France; YEU: Ker Daniau, Ile d'Yeu, Vendée, France; AIG: Baie de l'Aiguillon, Charente, France; BRO: Brouage, Charente, France; BOY: Boyardville, Charente, France; RLB: Ronce-les-Bains, Charente, France; BTZ: Biarritz, France; STB: Setubal, Portugal; FAR: Faro, Portugal; TEM: Temara (Rabat), Morocco; CAR: Cartagena, Spain; BAN: Banyuls, Roussillon, France; SET: Sète, France; RED: Ensuès-La Redonne, France; CHI: Chioggia, Italy; BUT: Butrintit, Albania; AGI: Agigea, Romania. 


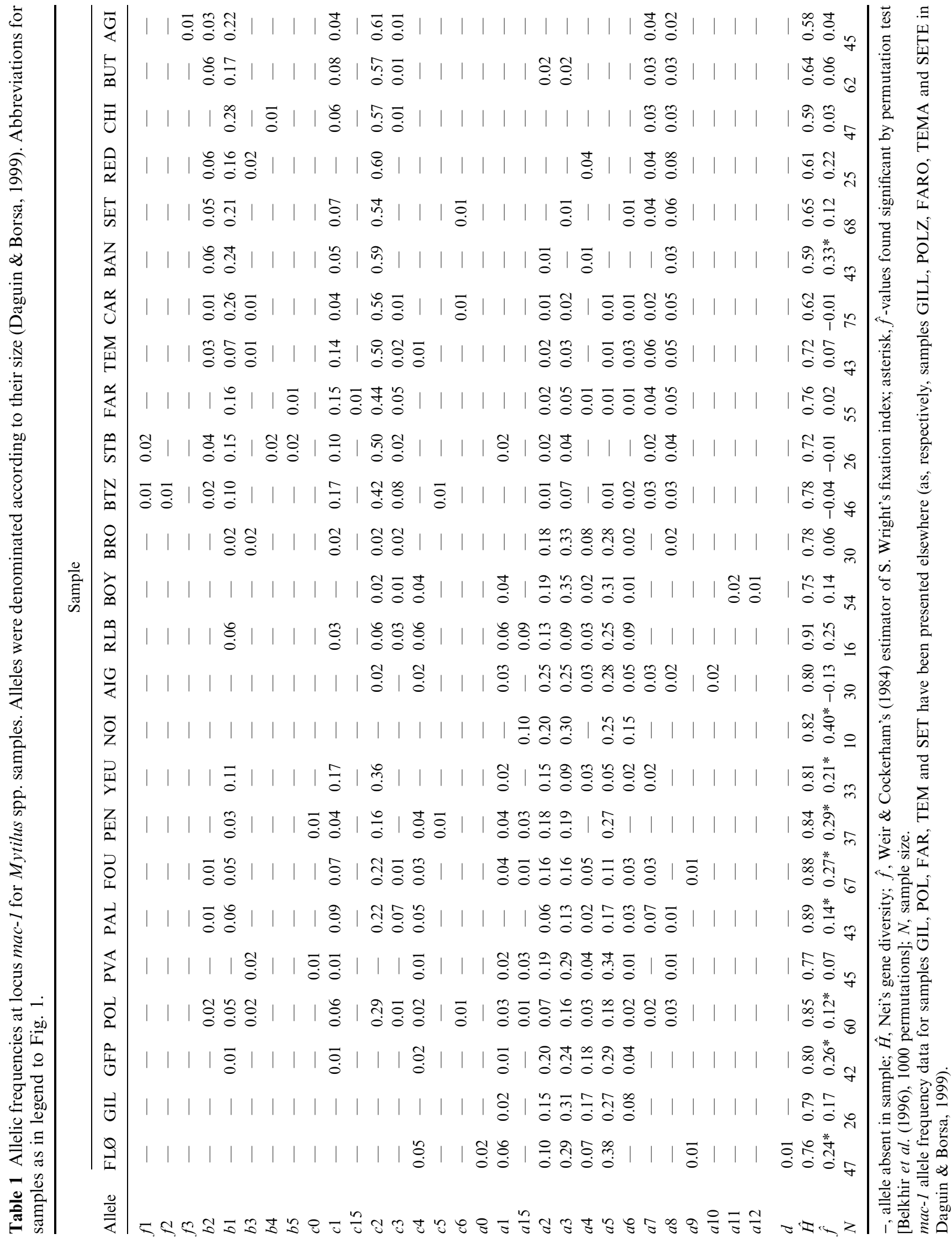

(c) The Genetics Society of Great Britain, Heredity, 86, 342-354. 
within the hybrid zone of M. edulis and M. galloprovincialis, as this has been geographically delimited on the basis of allozyme data (Skibinski \& Beardmore, 1979; Coustau et al., 1991). Allozyme frequency data have been reported in the literature for samples from some of these localities [POL (Polzeath, Cornwall): sample Polzeath of Beaumont et al. (1989); PVA (Pléneuf-ValAndré, Brittany), FOU (La Forêt-Fouesnant, Brittany), NOI (Noirmoutier, Vendée), BTZ (Biarritz, Basque Country): respectively, samples 3, 5, 7 and 9 of Coustau et al., 1991]. In order to assess the degree of genetic intergradation in the populations in the zone of sympatry, it was necessary to analyse reference samples for each species. Thus, samples FLØ (Flødevigen, Skagerrak), GIL (Gilleleje, Kattegat) and GFP (Grand-FortPhilippe, North Sea) were chosen as reference M. edulis because of their geographical location and according to allozyme data on samples collected nearby (Väinölä \& Hvilsom, 1991; Coustau et al., 1991). Samples STB (Setubal, Portugal), FAR (Faro, Portugal) and TEM (Temara, Atlantic coast of Morocco) were similarly chosen as reference $M$. galloprovincialis (see Sanjuan et al., 1994; Quesada et al., 1995c; Comesaña et al., 1998). Although reference M. galloprovincialis are usually sampled in the Mediterranean (e.g. Varvio et al., 1988; Coustau et al., 1991; Rawson et al., 1996), and the type locality for $M$. galloprovincialis is the coast of Roussillon in the Western Mediterranean (Lamarck, 1819), we here used samples from Atlantic (instead of Mediterranean) populations of $M$. galloprovincialis as the reference for this species, because of their genetic distinctness (see Introduction). Note that the two types from Linnaeus' collection of $M$. edulis that Bucquoy et al. (1898) chose as representative of the species were those collected in Esnandes (Baie de l'Aiguillon, Charente, France) and on the North Sea coast of England.

We here extended the geographical survey of genetic variation in European Mytilus galloprovincialis by analysing samples from the Western Mediterranean [Cartagena, Murcia, Spain (CAR); Banyuls, Roussillon, France (BAN); Sète, Languedoc, France (SET); EnsuèsLa Redonne, Provence, France (RED)], the Adriatic Sea [Chioggia, Italy (CHI); Butrintit, Albania (BUT)] and the Black Sea (Agigea, Romania: AGI) (Fig. 1). Allozyme surveys up to now have not detected significant geographical variation among $M$. galloprovincialis populations from the Western Mediterranean, the Adriatic Sea, and the Black Sea (Skibinski et al., 1983; Varvio et al., 1988; Coustau et al., 1991; McDonald et al., 1991; Väinölä \& Hvilsom, 1991; Sanjuan et al., 1994; Quesada et al., 1995c). Note that the geographical location of the CAR sample is between Almería and Alicante, a region where no mussel had been found up to now (Quesada et al., 1995c; Sanjuan et al., 1997).
After their collection, the mussels were preserved either alive on ice (samples POL, BOY, BRO, BTZ, SET; Fig. 1) or frozen (AIG, RLB, BUT; Fig. 1) or in alcohol (all the other samples) and sent to our laboratory for analysis.

\section{DNA extraction and amplification by polymerase chain reaction (PCR)}

DNAs were first extracted using the Chelex protocol (Walsh et al., 1991), where 0.5-2 mg adductor muscle tissue dissected from each individual was digested at $55^{\circ} \mathrm{C}$ overnight in a microfuge tube containing $6 \%$ Chelex resin (Biorad, Richmond CA, USA) and $12 \mathrm{U}$ proteinase $\mathrm{K}$ in $350 \mu \mathrm{L} \quad 0.1 \mathrm{~mm}$ Tris- $\mathrm{HCl} / 0.01 \mathrm{~mm}$ EDTA, pH 8.0 buffer. Samples consistently failing to PCR-amplify using Chelex-extracted DNA templates were subsequently subjected to phenol-chloroform DNA extraction, where 3-5 $\mathrm{mg}$ of dried adductor muscle tissue was incubated at $55^{\circ} \mathrm{C}$ overnight in a 50-mm Tris- $\mathrm{HCl}, 25 \mathrm{~mm}$ EDTA, 1\% SDS, pH 8.0 buffer containing $18 \mathrm{U}$ proteinase $\mathrm{K}$. This was followed by a two-round phenol-chloroform procedure. The nucleic acid pellet was then resuspended in $200 \mu \mathrm{L}$ deionized water and frozen at $-20^{\circ} \mathrm{C}$ until genotyping.

The DNA extracts were used as templates for PCR amplification of a portion of Intron 1 of the actin gene mac-1 (Ohresser et al., 1997) according to protocols detailed in Daguin \& Borsa (1999).

\section{Analysis of data}

Correspondence analysis (CA; Benzécri, 1982) was performed using the AFC procedure implemented in BIOMECO (Lebreton et al., 1990) on the matrix of allelic frequencies per sample. This method has been previously used in Mytilus by Coustau et al. (1991) on multiple-locus allozyme data. The beauty of CA is that it simultaneously expresses the genetic differences present in the data set and sorts out the contributions of each allele to these differences. Guinand (1996) showed that the eigenvalues of each CA's axis are analogous to partial $F_{\mathrm{ST}}$, Wright's coefficient of genetic differentiation between populations. We thus investigated the genetic relationships among samples within the zone of sympatry, and of the samples to reference $M$. edulis and M. galloprovincialis. Mediterranean M. galloprovincialis samples were placed as supplementary variables in the CA to assess their relationships to Atlantic M. galloprovincialis. All mac-1 alleles were taken into account in the analysis. [Coustau et al. (1991) pointed out that the occurrence of rare alleles (whose frequency in the total sample was $<0.01$ ) caused distortion on the factorial co-ordinates of samples and alleles. We addressed this 
potential problem by considering rare mac- 1 alleles as supplementary variables in the CA, and comparing it with the CA where all mac-1 alleles were active variables. Only negligible differences were noted leading us not to address the problem further.]

The occurrence of samples with allele frequencies intermediate between those of each species' reference samples reflects either intergradation or admixture. Intergradation, resulting from interbreeding, would correspond to Hardy-Weinberg genotype frequencies whereas admixture, defined as the simultaneous occurrence in a sample of individuals of either parental species, would translate into heterozygote deficiency (the Wahlund effect). Admixture may result from the recruitment at a site of swarms of larvae of the two species. Genotype frequency analysis may help to determine which one of these two models is the most appropriate. Correlations of alleles within individuals relative to the population were estimated using Weir \& Cockerham's (1984) estimator of $f$, the multiple-allele equivalent of Wright's $F_{\text {IS }}$. Random permutations of alleles in the matrix of individuals $\times$ genotypes were used to estimate the expected distribution of $\hat{f}$ under the null hypothesis $\hat{f}=0$. Estimations of $f$ and permutation tests were done using the GENETIX 3.3 software (Belkhir et al., 1996).

In order to simulate a Wahlund effect, we constructed two pools of individuals: a Mytilus edulis pool, including all individuals from the samples classified as $M$. edulis according to the CA (i.e. FLØ, GIL, GFP, PVA, AIG, BOY, BRO, but not NOI nor RLB) and an M. galloprovincialis pool including all individuals from the Atlantic M. galloprovincialis samples (BTZ, STB, FAR, and TEM). Then, we generated 10 replicates each of 11 pseudo-samples $(N=40)$ corresponding to 11 proportions of randomly chosen individuals from either pool (from $0 \%$ to $100 \%$ M. galloprovincialis by $10 \%$ increment). Weir \& Cockerham's $f$ was estimated for each replicate and was plotted against the co-ordinate along axis 1 of the CA for each pseudo-sample (i.e. after averaging allelic frequencies over the 10 replicates). A second-order polynomial regression on these points was used as the expected $f$ function.

\section{Results}

Thirty-one size alleles (ranging from $\approx 220 \mathrm{bp}$ to $\approx 420 \mathrm{bp}$ ) were detected in the total sample. Allelic frequencies per sample are presented in Table 1 . Whereas 15 of the alleles were represented in only one or two samples, 11 alleles were present in more than half of the samples. High levels of polymorphism were evidenced in every population sampled, as indicated by the range of gene diversity estimates (Table 1).
CA was conducted to explore the variation in allelic frequencies across samples, and to eventually link genetic differences to geography. Figure 2 parts $\mathrm{A}$ and B separately present the projections of samples and alleles on the plane defined by the first two factorial axes of the CA. More than $55 \%$ of the inertia of the data matrix (this can be considered as an analogue of the total variance in allelic frequency; Benzécri, 1982) was represented by the first axis of CA. All samples except two (NOI and RLB) were positioned along Axis 1, from a Mytilus edulis pole (extreme left of Axis 1) to a Mediterranean M. galloprovincialis pole (extreme right). Axis 1 thus essentially reflects the allele frequency gradient between the two species. All Atlantic M. galloprovincialis samples (STB, FAR, TEM) formed a cluster adjacent to the Mediterranean cluster of samples (BAN, SET, RED, CHI, BUT, AGI). This shows that Atlantic M. galloprovincialis are genetically homogeneous but slightly different from Mediterranean M. galloprovincialis as formerly reported (Daguin \& Borsa, 1999). The estimate of $\theta$ (Weir \& Cockerham, 1984) between these two groups of samples was $\hat{\theta}=0.018 \quad(P<0.001 ; 2000$ random permutations; Belkhir et al., 1996). Sample CAR clustered with the Mediterranean samples as expected from its geographical location, that is, east of the Almería-Oran oceanographic front (see Quesada et al., 1995c). Among the 12 populations sampled in the hybrid zone, one (BTZ) clustered with the three Atlantic M. galloprovincialis reference samples, four (AIG, BRO, BOY, PVA) clustered with the three $M$. edulis reference samples, five (YEU, PAL, POL, FOU, PEN) appeared as genetically intermediate between $M$. edulis and M. galloprovincialis, and two (RLB and NOI), recognized as M. edulis by their co-ordinates along Axis 1, appeared as distinct along Axis 2. As the sizes of the last two samples were also the lower, we reiterated the CA on allelic counts instead of allelic frequencies, thereby weighting samples by their size. This did not appreciably affect the positions of samples RLB and NOI relative to the other $M$. edulis samples (data not shown). The originality of these samples is attributable to the higher frequencies of alleles $a 15$ and $a 6$ as indicated by the contributions of the latter to Axis 2 (Table 2). Allele $a 15$ was also present in three (POL, FOU, PEN) of the five genetically intermediate samples and in PVA, another $M$. edulis sample from the hybrid zone, but was noticeably absent elsewhere (Table 1).

According to the ranking of samples along Axis 1, the hybrid zone did not appear as a clinal north-to-south transition zone between Mytilus edulis and M. galloprovincialis but instead as a patchwork of populations.

The positions of alleles on the first CA plane (Fig. 2B) and their relative contributions to Axis 1 (Table 2) 

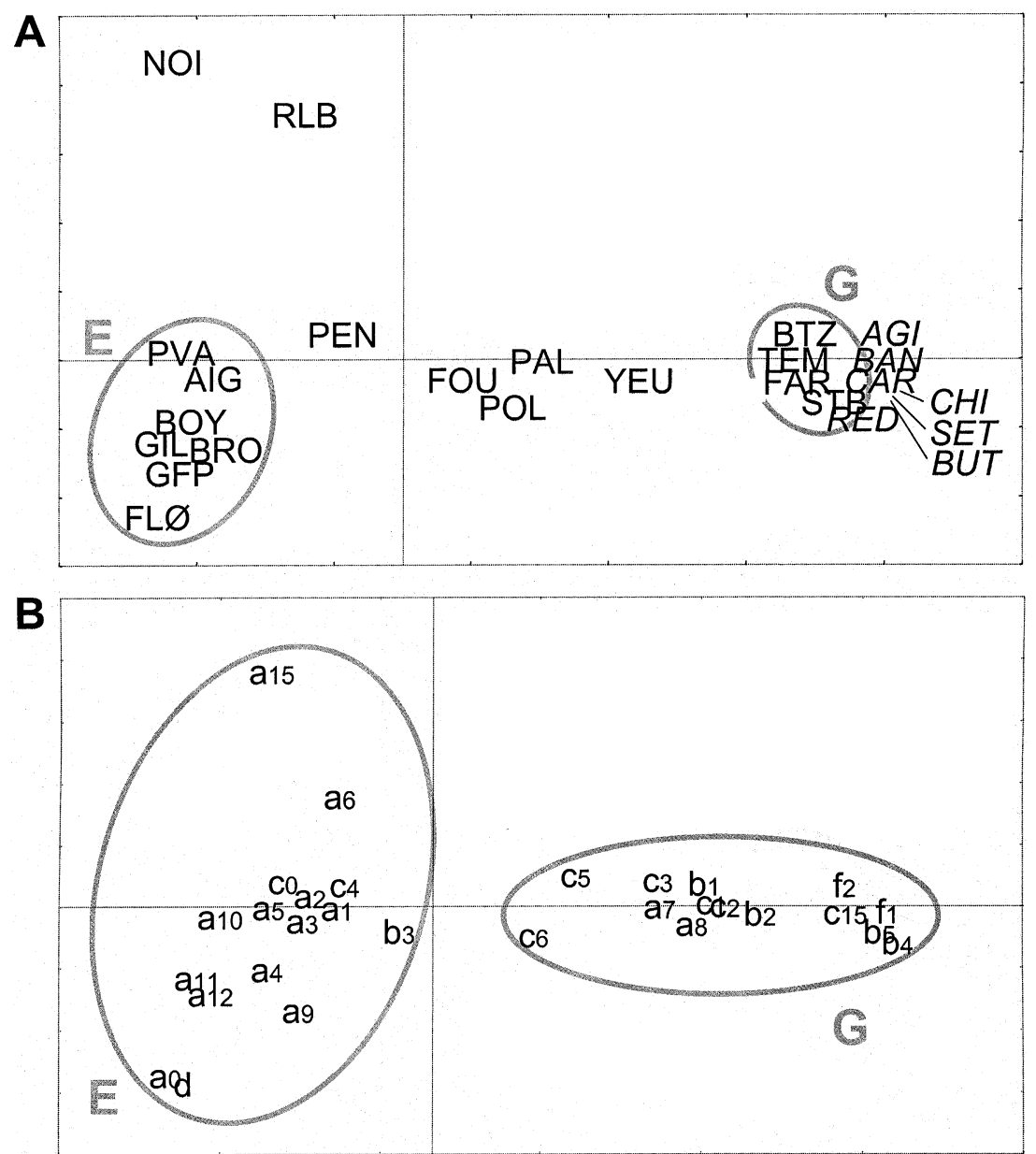

Fig. 2 Correspondence analysis (CA, Benzécri, 1982) on the matrix of allelic frequencies of Mytilus spp. samples from the north-eastern Atlantic and the Mediterranean. Inertias of CA-Axis 1 (horizontal) and CA-Axis 2 (vertical) were $55.3 \%$ and $10.0 \%$, respectively. (A) Scatter plot of samples on the first factorial plane. Grey contours delimit the clusters of M. edulis (E) and $M$. galloprovincialis $(\mathrm{G})$ reference samples. Abbreviations for samples as in legend to Fig. 1. Italics: M. galloprovincialis samples introduced as supplementary variables. (B) Scatter plot of alleles on the first factorial plane. Grey contours delimit the clusters of $M$. edulis (E) and M. galloprovincialis (G) alleles. indicate which alleles were responsible for the distinction between Mytilus edulis and M. galloprovincialis. The 31 alleles of the total sample were distributed as two distinct clusters along the first factorial axis, from alleles characteristic of $M$. galloprovincialis ( $b 1, c 1, c 2$ and $a 8$ for the most frequent and contributing alleles; see Table 2) to alleles characteristic of M. edulis ( $a 2, a 3$ and $a 5)$. This led us to consider that all alleles with positive (respectively, negative) co-ordinates along Axis 1 were characteristic of M. galloprovincialis (respectively, M. edulis).

Whether the occurrence of five genetically intermediate populations (YEU, PAL, POL, FOU, PEN) reflected intergradation or admixture can be gauged from the distribution of genotype frequencies. Table 1 gives the estimate of $f$ for each sample: all five genetically intermediate samples exhibited significant, positive $\hat{f}$-values indicating heterozygote deficiencies relative to Hardy-Weinberg expectations; the other significant $\hat{f}$-values, all positive, were for samples FLØ, GFP (that is, two of the Mytilus edulis reference samples), and BAN. The fact that heterozygote deficiency was already present in reference populations points to the possible existence of null alleles, making the interpretation of the positive $\hat{f}$-values in the intermediate populations uncertain. To test the hypothesis of admixture of NE Atlantic $M$. edulis and $M$. galloprovincialis, we therefore chose to compare the observed $\hat{f}$-values to the pseudo-distribution of $\hat{f}$ in a range of pseudo-samples generated by choosing variable proportions of individuals randomly re-sampled within either the pool of $M$. edulis samples (FLØ + GIL + $\mathrm{GFP}+\mathrm{PVA}+\mathrm{AIG}+\mathrm{BOY}+\mathrm{BRO}$ ) or the pool of NE Atlantic $M$. galloprovincialis samples (BTZ + $\mathrm{STB}+\mathrm{FAR}+\mathrm{TEM})$. Figure 3 shows the expectation of $\hat{f}$ for each admixture proportion, plotted against the first factorial co-ordinate of CA. The admixture hypothesis could not be rejected for any sample, except, perhaps, sample POL.

To remove the effect of null alleles - if present - in Mytilus edulis reference populations, alleles characteristic of each species were pooled into compound alleles $E$ (for M. edulis) and $G$ (for M. galloprovincialis) and the distribution of genotypes in each sample (Fig. 1) was reanalysed by recalculating $\hat{f}$. Allele-grouping ended up in suppressing heterozygote deficit in $M$. edulis reference samples since these consisted of $E E$ and $E G$ individuals 
Table 2 Correspondence analysis on Mytilus spp. samples characterized at locus mac-1: relative contributions of alleles and samples to the first two factorial axes, ranked in decreasing order. Mediterranean samples BUT, CHI, AGI, RED, SET, BAN were introduced as supplementary variables in the analysis. Abbreviations for samples as in legend to Fig. 1

\begin{tabular}{|c|c|c|c|c|c|}
\hline \multirow[b]{2}{*}{ Allele } & \multicolumn{2}{|c|}{ Contribution } & \multirow[b]{2}{*}{ Sample } & \multicolumn{2}{|c|}{ Contribution } \\
\hline & Axis 1 & Axis 2 & & Axis 1 & Axis 2 \\
\hline$c 2$ & 0.979 & 0.001 & TEM & 0.834 & 0.000 \\
\hline$a 5$ & 0.922 & 0.007 & FAR & 0.815 & 0.000 \\
\hline$c 1$ & 0.872 & 0.000 & BTZ & 0.774 & 0.001 \\
\hline$b 1$ & 0.842 & 0.003 & STB & 0.716 & 0.003 \\
\hline$a 3$ & 0.828 & 0.033 & PVA & 0.653 & 0.000 \\
\hline$a 2$ & 0.695 & 0.005 & GIL & 0.581 & 0.055 \\
\hline$a 8$ & 0.609 & 0.010 & $\mathrm{BRO}$ & 0.571 & 0.107 \\
\hline$b 2$ & 0.545 & 0.003 & GFP & 0.569 & 0.115 \\
\hline$a 7$ & 0.446 & 0.001 & YEU & 0.559 & 0.003 \\
\hline$c 3$ & 0.374 & 0.016 & $\mathrm{AIG}$ & 0.442 & 0.002 \\
\hline$f 1$ & 0.306 & 0.002 & BOY & 0.434 & 0.036 \\
\hline$b 5$ & 0.296 & 0.005 & FLØ & 0.408 & 0.138 \\
\hline$a 4$ & 0.289 & 0.214 & NOI & 0.350 & 0.531 \\
\hline$a 1$ & 0.185 & 0.000 & PAL & 0.255 & 0.000 \\
\hline$b 4$ & 0.169 & 0.004 & POL & 0.204 & 0.023 \\
\hline$c 15$ & 0.140 & 0.000 & RLB & 0.120 & 0.573 \\
\hline$f 2$ & 0.135 & 0.001 & PEN & 0.106 & 0.016 \\
\hline$c 4$ & 0.117 & 0.005 & $\mathrm{FOU}$ & 0.088 & 0.012 \\
\hline$a 6$ & 0.115 & 0.575 & CAR & - & - \\
\hline$a 15$ & 0.100 & 0.835 & $\mathrm{BAN}$ & - & - \\
\hline$a 0$ & 0.062 & 0.117 & SET & - & - \\
\hline$d$ & 0.062 & 0.117 & RED & - & - \\
\hline$a 11$ & 0.050 & 0.023 & $\mathrm{CHI}$ & - & - \\
\hline$a 12$ & 0.050 & 0.023 & BUT & - & - \\
\hline$c 0$ & 0.043 & 0.003 & AGI & - & - \\
\hline$a 10$ & 0.038 & 0.001 & & & \\
\hline$a 9$ & 0.034 & 0.095 & & & \\
\hline$c 5$ & 0.032 & 0.005 & & & \\
\hline$c 6$ & 0.007 & 0.005 & & & \\
\hline b3 & 0.006 & 0.017 & & & \\
\hline$f 3$ & 0.000 & 0.000 & & & \\
\hline
\end{tabular}

only (Fig. 1). Here the null hypothesis $\left(H_{0}\right)$ of HardyWeinberg equilibrium at a biallelic $(E, G)$ locus was tested, which is equivalent to testing panmixia between M. edulis and M. galloprovincialis. Values of $\hat{f}$ remained high for samples FOU $(\hat{f}=0.263 ; P<0.03$; one-tailed test) and PEN ( $\hat{f}=0.279 ; P<0.05)$ and dropped for samples YEU $(\hat{f}=0.014)$, POL $(\hat{f}=0.039)$ and PAL $(\hat{f}=-0.110)$. Thus $H_{0}$ could be rejected only for samples FOU and PEN. The heterozygote deficiency initially found in sample YEU therefore may have been caused by null alleles. Altogether the above results suggest that only two samples (FOU, PEN) consist more of some mixture of $M$. edulis and $M$. galloprovincialis genotypes rather than of a hybrid population.

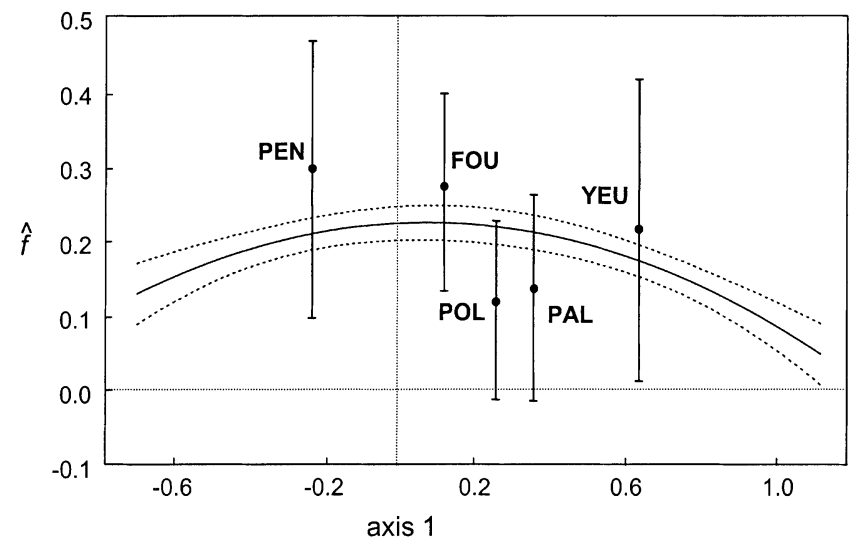

Fig. 3 Plot of Weir \& Cockerham's (1984) $\hat{f}$-values against coordinate along axis 1 of CA, for five genetically intermediate Mytilus spp. samples. Comparison with expected heterozygote deficiency under the admixture hypothesis (solid line, obtained by 2 nd-order polynomial regression on a range of pooled random subsamples of reference $M$. edulis and M. galloprovincialis). Vertical bars, 95\% bootstrap confidence intervals (1000 pseudo-samples). Dotted lines delimit 95\% confidence area around regression line. Abbreviations for samples as in legend to Fig. 1.

Figure 1 reports the genotypic ( $E E, E G, G G)$ composition of these and the other samples. Two reference samples for Mytilus edulis (FLØ and GIL) and two Mediterranean M. galloprovincialis samples (CHI and AGI) consisted of $100 \% E E$ and $G G$ genotypes, respectively. Atlantic M. galloprovincialis samples contained $E G$ individuals at a frequency that was geographically homogeneous; they possessed $M$. edulis alleles $(a 1, a 2, a 3, a 4, a 5, a 6, b 3$, and $c 4)$ at a total frequency of $0.08-0.11$. This was in contrast with Mediterranean M. galloprovincialis, in which the frequencies of $M$. edulis alleles were marginal if present (Fig. 1; Table 2). Overall, four zones could be distinguished along the European coastline (Fig. 1). (1) A pure Mytilus edulis region, which extends from the eastern end of the English Channel to Skagerrak and Kattegat; (2) the zone of sympatry between $M$. edulis and $M$. galloprovincialis, which includes samples from south-west Britain, Brittany and Charente; this zone consists of a mosaic of populations that include pure $M$. edulis at some localities, putative $M$. edulis $\times$ $M$. galloprovincialis hybrid populations at some other localities, the remainder consisting of mixtures of M. edulis, M. galloprovincialis and their hybrids; (3) a geographically homogeneous Atlantic M. galloprovincialis region, which extends from the Basque coastline to north-western Africa, and where alleles characteristic of M. edulis have a frequency of between 0.08 and 0.11 ; (4) the Mediterranean Sea, which harbours a distinct 
M. galloprovincialis form, where mac- 1 alleles characteristic of $M$. edulis have a total frequency $\leq 0.06$.

\section{Discussion}

\section{Genotypic composition of hybrid zone samples}

The present study is the first that uses noncoding nuclear DNA markers for describing the geographical structure of the hybrid zone of Mytilus edulis and M. galloprovincialis. Intron-length polymorphism at locus mac-1 shows a mosaic structure: six out of the 11 samples from the hybrid zone were $M$. edulis-like and the five other samples were distributed along the genetic unidimensional gradient between $M$. edulis and M. galloprovincialis, without congruence with geography.

The genetically intermediate samples found in the zone of sympatry all exhibited significant heterozygote deficiencies. For two of these (FOU and PEN), the heterozygote deficiency reflected some degree of admixture of individuals of each species. Other explanations are needed to account for the heterozygote deficiency in the other genetically intermediate samples of the hybrid zone, as in some samples outside it (FLØ, GFP, BAN). The null allele hypothesis where apparent excesses of homozygotes would be due to mispriming was tested in Mytilus edulis (FLØ), M. galloprovincialis (SET), and in a hybrid zone population (POL) by comparing the individual genotypes with two different primer pairs (Daguin \& Borsa, 1999; unpublished). There was no evidence for this type of null allele, but one cannot exclude the presence of undetected large deletions encompassing both primer sites at either side of the target portion of template DNA. The heterozygote deficiencies may have other causes (e.g. aneuploidy, selection; see Gaffney, 1994 and Raymond et al., 1997 for in-depth discussions of this phenomenon). Since there is evidence of correlation between diagnostic allele frequencies and age elsewhere in the hybrid zone (e.g. Gardner \& Skibinski, 1988), the deviations from HardyWeinberg proportions may also depend on the age distribution of a sample.

\section{Comparison with allozyme data}

The comparison between allozyme (Skibinski et al., 1983; Coustau et al., 1991) and mac-1 data in the European hybrid zone between Mytilus edulis and $M$. galloprovincialis consistently points out a mosaic pattern in the distribution of populations. (1) Both allozyme (Coustau et al., 1991) and mac-l data (present study) make it possible to assign the mussels from Noirmoutier, Charente to M. edulis. However, unlike locus mac-1, allozyme data did not distinguish these from North Sea M. edulis [see Fig. 2 of Coustau et al. (1991)]. This conclusion resulted from a CA based on these authors' Est-D and Mpi data (that is, the two most diagnostic allozyme loci) and using their Atlantic $M$. galloprovincialis sample (Biarritz) as the reference for this species (results not shown). (2) mac-l data showed that partial admixture between $M$. edulis and M. galloprovincialis occurs at Forêt-Fouesnant, Brittany. This again was consistent with the allelic frequency and heterozygote deficiency data at diagnostic allozyme loci Est-D and Mpi (Coustau et al., 1991; their Fig. 3 and Table 2, respectively). (3) The sample from PléneufVal-André (Saint-Brieuc, Brittany), taken from a farmed stock, was $M$. edulis according to mac-1. The Saint-Brieuc sample collected in the wild by Coustau et al. (1991) was a mixture of M. edulis, M. galloprovincialis, and their hybrids. M. edulis spat are imported into the Bay of Saint-Brieuc every year from Baie de l'Aiguillon (Charente) for cultivation. We here confirmed that farmed stocks in the Bay of Saint-Brieuc are identical to the mussels from Baie de l'Aiguillon (see Fig. 2, samples AIG, BRO, BOY). (4) mac-1 data showed that the sample POL is more hybrid than mixed, as implicitly suggested by previous allozyme results (Beaumont et al., 1989).

\section{Mosaicism of hybrid zones in Mytilus: patterns, hypotheses}

Hybridization between Mytilus species may show different spatial patterns depending on the taxa involved and on the location. Mosaicism appears to be a common feature of Mytilus hybrid zones (Koehn et al., 1984; McDonald \& Koehn, 1988; Sarver \& Foltz, 1993; Bates \& Innes, 1995; Saavedra et al., 1996; Suchanek et al., 1997; Comesaña et al., 1999; Rawson et al., 1999).

Explanations for mosaicism include the following. (1) Endogenous selection against hybrids (tension zone). The coexistence of parental species and hybrids along the hybrid zone would be maintained because hybrid fitness would be reduced; the geographical patchiness of the hybrid zone would be an effect of larval transport, which causes swarms of larvae to land at a place distant from the place of fertilization. (2) Mosaicism of habitat. It is here assumed that mosaicism arises from adaptation of the two parental forms to different and intermingled environments (Rand \& Harrison, 1989; Arnold, 1997). (3) Transplantation. As suggested by Suchanek et al. (1997), recurrent transplantation of either species by means of ships may play an important role in maintaining their presence as patches at unfavourable locations, where they do not reproduce; hence their patchy distribution. The data available to date are not sufficient to test the above hypotheses. 


\section{Alleles endemic to the hybrid zone}

Several samples from the hybrid zone harboured at substantial frequencies mac- 1 size alleles $(a 6, a 15)$ that were absent or rare in both reference Mytilus edulis and M. galloprovincialis. Allozymes coined hybrizymes by Woodruff (1989) have been found in hybrid zones, where they are endemic.

Selection and genetic drift have been invoked as phenomena responsible for the maintaining of hybrizymes at moderately high frequency (Barton \& Hewitt, 1985; Woodruff, 1989), but these do not appear as satisfactory explanations for the increase in frequency of some mac- 1 alleles in mussels. First, this genetic marker is not coding, and there is no reason to suspect that small changes in intron size should be advantageous in the zone of hybridization and only there. Second, genetic drift is unlikely to be perceptible unless a population is isolated and of small effective population size. Alternatively, the presence of these alleles in French Atlantic populations, including some Mytilus edulis populations, may simply reflect the genetic distinctness of $M$. edulis in this area.

\section{Genetic variation outside the hybrid zone}

South of the hybrid zone, Atlantic Mytilus galloprovincialis samples harboured M. edulis mac-1 alleles ( $a 2, a 3$, a5) at substantial frequencies. These were also present but rare in some Western Mediterranean and Adriatic Sea M. galloprovincialis samples. The difference in the frequency of $M$. edulis alleles was mostly responsible for the genetic differentiation between Atlantic and Mediterranean $M$. galloprovincialis populations at locus mac-1. A similar trend was evident at allozyme loci $A p$ and, perhaps, Gpi (Daguin \& Borsa, 2000) but not at the four other loci (Est-D, Lap, Mpi, Odh) examined so far in M. edulis, Atlantic M. galloprovincialis, and Mediterranean M. galloprovincialis (Coustau et al., 1991; Sanjuan et al., 1994).

If $M$. edulis mac- 1 alleles were currently introgressing Atlantic M. galloprovincialis populations, a regular cline would be expected from Baie de l'Aiguillon where the frequency of $M$. edulis alleles reaches $100 \%$, to the southernmost Atlantic M. galloprovincialis sample (Morocco). Instead, M. edulis allele frequencies in Atlantic M. galloprovincialis populations were homogeneous from the Basque Country to Morocco. We therefore propose that the presence of mac- 1 alleles $a 2$, $a 3$ and $a 5$ in, mostly, Atlantic M. galloprovincialis results from their past introgression by $M$. edulis. By contrast, the lack of similar pattern for $4 / 6$ allozyme loci suggest that introgression is counter-selected at the latter. We suppose that Mediterranean M. galloprovincialis were less affected by this presumed introgression event because of their remoteness (which is consistent with the absence of $M$. edulis alleles in the samples from the more remote regions: northern Adriatic and Black Sea). The differences may also have been enhanced and maintained to the present by the hydrological discontinuity coincident with the Almería-Oran oceanographic front (Tintore et al., 1988; Quesada et al., 1995a,c).

Although the above scenario receives support from mtDNA RFLP and sequence data (Quesada et al., 1998; Hilbish et al., 2000; see Introduction), one cannot exclude that inadvertent introduction of alien mussels may have marginally contributed to the current distribution of mac-1 alleles throughout the area studied.

\section{Conclusion}

Allele-frequency data at a noncoding nuclear-DNA marker partly confirmed the main results of former allozyme surveys in showing that Mytilus edulis and M. galloprovincialis along the Atlantic European coasts meet and interbreed, and that the zone of contact and hybridization overall consists of a geographical mosaic of pure, hybrid, or mixed populations of either species. Despite extensive hybridization at some geographically intermediate locations, presumably neutral mac-1 alleles do not appear to presently cross the hybrid zone, which therefore probably acts as a barrier to gene flow. The present occurrence of $M$. edulis-like alleles in Atlantic and, to a lesser extent, Mediterranean M. galloprovincialis can be explained by past introgression by M. edulis. This was also evident at some allozyme loci. At other allozyme loci (Coustau et al., 1991; Sanjuan et al., 1994; Quesada et al., 1995c) the patterns of geographical variation in $M$. galloprovincialis were consistent with a scenario of vicariance followed by secondary intergradation.

\section{Acknowledgements}

We are grateful to C. Borsa, P. Boudry, F. Chevalier, L. Chikhi, J.-C. Cocheril, E. Diaz Almela, O. Guelorget, D. Jollivet, S. Launey, A. Leitao, C. Lemaire, E. Lopes, M. Naciri, M. Ohresser, J. Panfili, M. Raymond, C. Thiriot-Quiévreux, J. Trandafirescu and C. Tsigenopoulos for arranging or participating in the collection of samples; to K. Belkhir for help with computer programming and to $\mathrm{S}$. Ramos Caetano for participating in laboratory analyses; to J. Panfili and M. Raymond for help with bibliographic search; to N. Bierne, J.-F. Cosson, P. David, B. Delay, M. Raymond, and two anonymous referees for helpful comments; to C. Lemaire for helpful tips. This research was funded by Laboratoire Génome Populations Interactions (contracts IFREMER 
URM 16 nos 985556400 and 995 556355). C. Daguin benefited from a 3-year Ph.D. studentship allocated by MENRT (contract no. 97-5-33465). P. Borsa is affiliated to the Institut de Recherche pour le Développement, Paris.

\section{References}

ARNOLD, M. L. 1997. Natural Hybridization and Evolution. Oxford University Press, New York.

BARTON, N. H. AND HewitT, G. M. 1985. Analysis of hybrid zones. Ann. Rev. Ecol. Syst., 16, 113-148.

BARTON, N. H. AND HEWITT, G. M. 1989. Adaptation, speciation and hybrid zones. Nature, 341, 497-503.

BATES, J. A. AND INNES, D. J. 1995. Genetic variation among populations of Mytilus spp. in eastern Newfoundland. Mar. Biol., 124, 417-424.

BEAUMONT, A. R., SEED, R. AND GARCIA-MARTINEZ, P. 1989. Electrophoretic and morphometric criteria for the identification of the mussels Mytilus edulis and Mytilus galloprovincialis. In: Ryland, J. S. and Tyler, P. A. (eds) Reproduction, Genetics and Distributions of Marine Organisms, pp. 251-257. Olsen \& Olsen, Fredensborg, Denmark.

BELKHIR, K., BORSA, P., GOUDET, J., CHIKHI, L. ET AL. 1996. GENETIX, Version 3.0, Logiciel sous Windows $^{\mathrm{TM}}$ pour la Génétique des Populations. Université de Montpellier 2, Montpellier, France.

BENZÉCRI, J.-P. 1982. L'analyse des Données. 2. L'Analyse des Correspondances. Dunod, Paris.

BEYNON, C. M. AND SKIBINSKI, D. O. F. 1996. The evolutionary relationships between three species of mussels (Mytilus) based on anonymous DNA polymorphisms. J. Exp. Mar. Biol. Ecol., 203, 1-10.

BUCQUOY, E., DAUTZENBERG, P. AND DOLlFus, G. 1898. Les Mollusques Marins du Roussillon. II. Pélécypodes. Avec Atlas de 99 planches en Phototypie. J.-B. Baillière \& Fils, Paris.

COMESAÑA, A. S. AND SANJUAN, A. 1997. Microgeographic allozyme differentiation in the hybrid zone of Mytilus galloprovincialis and M. edulis on the continental European coast. Helg. Meeresunters., 51, 107-124.

COMESAÑA, A. S., POSADA, D. AND SANJUAN, A. 1998. Mytilus galloprovincialis in northern Africa. J. Exp. Mar. Biol. Ecol., 223, 271-283.

COMESAÑA, A. S., TORO, J. E., INNES, D. J. AND THOMPSON, R. J. 1999. A molecular approach to the ecology of a mussel (Mytilus edulis - M. trossulus) hybrid zone on the east coast of Newfoundland, Canada. Mar. Biol., 133, 213-221.

CÔRTE-REAL, H. S. B. M., DIXON, D. R. AND HOLLAND, P. W. H. 1994. Intron-targeted PCR, a new approach to survey neutral DNA polymorphism in bivalve populations. Mar. Biol., 120, 407-413.

COUSTAU, C., RENAUd, F. AND DELAY, B. 1991. Genetic characterization of the hybridization between Mytilus edulis and $M$. galloprovincialis on the Atlantic coast of France. Mar. Biol., 111, 87-93.

DAGUIN, C. AND BORSA, P. 1999. Genetic characterisation of Mytilus galloprovincialis Lmk. in North West Africa using nuclear DNA markers. J. Exp. Mar. Biol. Ecol., 235, 55-65.
DAGUIN, C. AND BORSA, P. 2000. Genetic relationships of Mytilus galloprovincialis Lmk. populations worldwide: evidence from nuclear-DNA markers. Geol. Soc. Lond. Spec. Publ., 177, 389-397.

DIEHL, W. J. AND KOEHN, R. K. 1985. Multiple-locus heterozygosity, mortality and growth in a cohort of Mytilus edulis. Mar. Biol., 88, 265-271.

EDWARDS, C. A. AND SKIBINSKI, D. O. F. 1987. Genetic variation of mitochondrial DNA in mussel (Mytilus edulis and M. galloprovincialis) populations from South West England and South Wales. Mar. Biol., 94, 547-556.

GAFFNEY, P. M. 1994. Heterosis and heterozygote deficiencies in marine bivalves: more light? In: Beaumont, A. R. (ed.) Genetics and Evolution of Marine Organisms, pp. 146-153. Chapman \& Hall, London.

GARDNER, J.P. A. 1994. The structure and dynamics of naturally occurring hybrid Mytilus edulis Linnaeus, 1758 and Mytilus galloprovincialis Lamarck, 1819 (Bivalvia: Mollusca) populations: review and interpretation. Arch. Hydrobiol., Suppl. 99, 37-71.

GARDNER, J. P. A. AND SKIBINSKI, D. O. F. 1988. Historical and size-dependant genetic variation in hybrid mussel populations. Heredity, 61, 93-105.

GUINAND, B. 1996. Use of a multivariate model using allele frequency distributions to analyse patterns of genetic differentiation among populations. Biol. J. Linn. Soc., 58, 173-195.

HARE, M. P., KARL, S. A. AND AVISE, J. C. 1996. Anonymous nuclear DNA markers in the American oyster and their implications for the heterozygote deficiency phenomenon in marine bivalves. Mol. Biol. Evol., 13, 334-345.

HARRISON, R. G. 1993. Hybrids and hybrid zones: historical perspective. In: Harrison, R. G. (ed.) Hybrid Zones and the Evolutionary Process, pp. 3-12. Oxford University Press, New York, Oxford.

HEATH, D. D. AND HILBISH, T. J. 1998. Mytilus protamine-like sperm-specific protein genes are multicopy, dispersed, and closely associated with hypervariable RFLP regions. Genome, 41, 587-596.

HILBISH, T. J., MULLINAX, A., DOLVEN, S. I. AND MEYER, A. 2000. Origin of the antitropical distribution pattern in marine mussels (Mytilus spp.): routes and timing of transequatorial migration. Mar. Biol., 136, 69-77.

inoue, K., WAite, J. H., MATSUOKA, M., ODO, S. ET AL. 1995. Interspecific variations in adhesive protein sequences of Mytilus edulis, M. galloprovincialis and M. trossulus. Biol. Bull., 189, 370-375.

INOUE, K., ODO, S., NODA, T., NAKAO, S. ET AL. 1997. A possible hybrid zone in the Mytilus edulis complex in Japan revealed by PCR markers. Mar. Biol., 128, 91-95.

KARL, S. A. AND AVISE, J. C. 1992. Balancing selection at allozyme loci in oysters: implications from nuclear RFLPs. Science, 256, 100-102.

KOEHN, R. K. AND HILBISH, T. J. 1987. The adaptive significance of genetic variation. Am. Sci., 75, 134-141.

KOEHN, R. K., HALL, J. G., INNES, D. J. AND ZERA, A. J. 1984. Genetic differentiation of Mytilus edulis in eastern North America. Mar. Biol., 79, 117-126. 
KOEHN, R. K., DIEHL, W. J. AND SCOTT, T. M. 1988. The differential contribution by individual enzymes of glycolysis and protein catabolism to the relationship between heterozygosity and growth rate in the coot clam, Mulinia lateralis. Genetics, $\mathbf{1 1 8}$, $121-130$.

LAMARCK, J.-B. DE. 1819. Histoire Naturelle des Animaux sans Vertèbres. Librairie Verdière, Paris.

LEBRETON, J.-D., ROUX, M., BANCO, G. AND BACOU, A.-M. 1990. віомесо (Biométrie-écologie), Logiciel d'Écologie Statistique pour PC et Compatibles, version 3.9. Centre National de la Recherche Scientifique, Montpellier, France.

LEMAIRE, C., ALLEGRUCCI, G., NACIRI, M., BAHRI-SFAR, L. ET $A L$. 2000. Do discrepancies between microsatellite and allozyme variation reveal differential selection between sea and lagoon in the sea bass (Dicentrarchus labrax)? Mol. Ecol., 9, $457-467$.

MCDONALD, J. H. AND KOEHN, R. K. 1988. The mussels Mytilus galloprovincialis and $M$. trossulus on the Pacific coast of North America. Mar. Biol., 99, 111-118.

MCDONALD, J. H., SEED, R. AND KOEHN, R. K. 1991. Allozymes and morphometric characters of three species of Mytilus in the Northern and Southern hemispheres. Mar. Biol., 111, 323-333.

MITTON, J. B. AND KOEHN, R. K. 1973. Population genetics of marine pelecypods. III. Epistasis between functionally related enzymes of Mytilus edulis. Genetics, 73, 487-496.

OHRESSER, M., BORSA, P. AND DELSERT, C. 1997. Intron-length polymorphism at the actin gene locus mac-1: a genetic marker for population studies in the marine mussels Mytilus galloprovincialis Lmk. and M. edulis L. Mol. Mar. Biol. Biotech., 6, 123-130.

POGSON, G. H., MESA, K. A. AND BOUTILIER, R. G. 1995. Genetic population structure and gene flow in the Atlantic cod Gadus morhua - a comparison of allozyme and nuclear RFLP loci. Genetics, 139, 375-385.

QUESADA, H., BEYNON, C. M. AND SKIBINSKI, D. O. F. 1995a. A mitochondrial DNA discontinuity in the mussel Mytilus galloprovincialis: Pleistocene vicariance biogeography and secondary intergradation. Mol. Biol. Evol., 12, 521-524.

QUESADA, H., WENNE, R. AND SKIBINSKI, D. O. F. 1995 b. Differential introgression of mitochondrial DNA across species boundaries within the marine mussel genus Mytilus. Proc. R. Soc. B, 262, 51-56.

QUeSADA, H., ZAPATA, C. AND ALVAREZ, G. 1995c. A multilocus allozyme discontinuity in the mussel Mytilus galloprovincialis: the interaction of ecological and life-history factors. Mar. Ecol. Prog. Ser., 116, 99-115.

QUESADA, H., GALLAGHER, C., SKIBINSKI, D. A. G. AND SKIBINSKI, D. O. F. 1998. Patterns of polymorphism and gene flow of gender-associated mitochondrial DNA lineages in European mussel populations. Mol. Ecol., 7, 1041-1051.

RAND, D. M. AND HARRISON, R. G. 1989. Ecological genetics of a mosaic hybrid zone: mitochondrial, nuclear, and reproductive differentiation of crickets by soil type. Evolution, 43, 432-449.

RAWSON, P. D. AND HILBISH, T. J. 1995. Evolutionary relationships among the male and female mt DNA lineages in the Mytilus edulis species complex. Mol. Biol. Evol., 12, 893-901.
RAWSON, P. D. AND HILBISH, T. J. 1998. Asymmetric introgression of mitochondrial DNA among European populations of blue mussels (Mytilus spp.). Evolution, 52, 100-108.

RAWSON, P. D., JOYNER, K. L., MEETZE, K. AND HILBISH, T. J. 1996. Evidence for intragenic recombination within a novel genetic marker that distinguishes mussels in the Mytilus edulis species complex. Heredity, 77, 599-607.

RAWSON, P. D., AGRAWAL, V. AND HILBISH, T. J. 1999. Hybridization between the blue mussels Mytilus galloprovincialis and $M$. trossulus along the Pacific coast of North America: evidence for limited introgression. Mar. Biol., 134, 201-211.

RAYMOND, M., VÄÄNTÖ, R. L., THOMAS, F., ROUSSET, F. ET AL. 1997. Heterozygote deficiency in the mussel Mytilus edulis species complex revisited. Mar. Ecol. Prog. Ser., 156, 767-779.

SAAVEDRA, C., STEWART, D. T., STANWOOD, R. R. AND ZOUROS, E. 1996. Species-specific segregation of gender-associated mitochondrial DNA types in an area where two mussel species (Mytilus edulis and M. trossulus) hybridize. Genetics, 143, 1359-1367.

SANJUAN, A., ZAPATA, C. AND ALVAREZ, G. 1994. Mytilus galloprovincialis and Mytilus edulis on the coasts of the Iberian peninsula. Mar. Ecol. Prog. Ser., 113, 131-146.

SANJUAN, A., COMESAÑA, A. S. AND DE CARlos, A. 1996. Macrogeographic differentiation by mtDNA restriction site analysis in the SW European Mytilus galloprovincialis. J. Exp. Mar. Biol. Ecol., 198, 89-100.

SANJUAN, A., ZAPATA, C. AND Alvarez, G. 1997. Genetic differentiation in Mytilus galloprovincialis Lmk. throughout the world. Ophelia, 47, 13-31.

SARVER, S. K. AND FOLTZ, D. W. 1993. Genetic population structure of a species complex of the blue mussel (Mytilus spp.). Mar. Biol., 117, 105-112.

SEED, R. 1992. Systematics, evolution and distribution of mussels belonging to the genus Mytilus: an overview. Am. Malacol. Bull., 9, 123-137.

SKIBINSKI, D. O. F. AND BEARDMORE, J. A. 1979. A genetic study of intergradation between Mytilus edulis and Mytilus galloprovincialis. Experientia, 35, 1442-1444.

SKIBINSKI, D. O. F., BEARDMORE, J. A. AND CROSS, T. F. 1983. Aspects of the population genetics of Mytilus (Mytilidae; Mollusca) in the British Isles. Biol. J. Linn. Soc., 19, 137-183.

SUCHANEK, T. H., GELLER, J. B., KREISER, B. R. AND MITTON, J. B. 1997. Zoogeographic distributions of the sibling species Mytilus galloprovincialis and M. trossulus (Bivalvia: Mytilidae) and their hybrids in the North Pacific. Biol. Bull., 193, 187-194.

Tintore, J. L. A., Violette, P. E., BlADE, I. AND CRUZADO, A. 1988. A study of an intense density front in the eastern Alboran sea: the Almería-Oran front. J. Phys. Oceanogr., 18, 1384-1397.

VÄINÖLÄ, R. AND HVILSOM, M. M. 1991. Genetic divergence and a hybrid zone between Baltic and North Sea Mytilus populations. Biol. J. Linn. Soc., 43, 127-148.

VARVIO, S.-L., KOEHN, R. K. AND VÄINÖLÄ, R. 1988. Evolutionary genetics of the Mytilus edulis species complex in the North Atlantic region. Mar. Biol., 98, 51-60. 
WALSH, P. S., METZGER, D. A. AND HIGUSHI, R. 1991. Chelex 100 as a medium for simple extraction of DNA for PCR-based typing from forensic material. Biotechniques, 10, 506-513.

WEIR, B. S. AND COCKERHAM, C. C. 1984 . Estimating $F$-statistics for the analysis of population structure. Evolution, 38, $1358-1370$
wOODRUFF, D. S. 1989. Genetic anomalies associated with Cerion hybrid zones: the origin and maintenance of new electrophoretic variants called hybrizymes. Biol. J. Linn. Soc., 36, 281-294. 